\title{
Comparison between the short-term observed and long-term estimated wind power density using Artificial Neural Networks. A case study
}

\author{
S Velázquez ${ }^{1}$, JA. Carta ${ }^{2}$ \\ ${ }^{1}$ Department of Electronics and Automatics Engineering, University of Las Palmas de Gran Canaria, Campus de Tafira s/n, \\ 35017 Las Palmas de Gran Canaria, Canary Islands (Spain). \\ Tel.: +34 9284596 71, Fax: +34928 457319 .E-mail address: svelazquez@diea.ulpgc.es \\ ${ }^{2}$ Department of Mechanical Engineering, University of Las Palmas de Gran Canaria, \\ Campus de Tafira s/n, 35017 Las Palmas de Gran Canaria, Canary Islands ( Spain). \\ Tel.: +34 9284510 00, Fax: +34928 451483 .E-mail address: jcarta@dim.ulpgc.es
}

\begin{abstract}
The economic feasibility of a wind project is dependent on the wind regime since it relies on the power output of the turbines over the installation's working life. Consequently, the interannual variability of wind speed at a potential wind energy conversion site is an issue of capital importance.
\end{abstract}

Usually a wind data measurement campaign is limited to a period no longer than one year (i.e. short-term). Therefore, the process of decision-making for wind farm constructors must be based in this short-term data.

Various methods have been proposed in the scientific literature for estimation of the long-term wind speed characteristics at such sites. These methods use simultaneous measurements of the wind speed at the site in question and at one or several nearby reference sites with a long history of wind data measurements.

In this paper, long-term wind power densities which have been estimated through the use Artificial Neural Networks (ANNs), will be compared to those which have been calculated by means of the short-term wind data (i.e. considered to be representative of long-term wind performance).

Mean hourly wind speeds and directions calculated in a 10 year period of time at six weather stations located on six different islands in the Canarian Archipelago (Spain) were used in this study.

Among the different conclusions which this study revealed, we can highlight that the wind resource estimation based on ANNs is better than that dependant on short-term wind data. This is true when the correlation coefficient between the reference and candidate weather station is of 0.6 .

Keywords: Wind Power, Long-Term, Artificial Neural Network, Wind Speed, Wind Farm

\section{Introduction}

Given that there is a cubic relationship between wind speed and wind power density, it is understandable that the electrical energy obtainable with a wind power turbine is very conditioned to the wind regime.

As stated by Hiester and Pennell [1], the interannual variability of wind speed at a potential wind energy conversion site is a very important issue.

The first concern about a site under consideration for a wind power station is with the long-term (many years) mean wind speed [2-8].

However, on many occasions there are no historical wind data measurement series available for the candidate site. This is a major obstacle for the assessment of the economic feasibility of a wind farm project on a time horizon equivalent to the useful life of the installation [911].

One option that can be used to get around this lack of data for the candidate site is to conduct a wind data measurement campaign that covers a sufficient number of years. According to Hiester and Pennell [1], accurate estimation of the mean values of the wind performance is difficult with less than 10 years worth of data. This option entails an inevitable increase in the costs of the measurement campaign and, more importantly, the postponement of any final decision-taking for a normally unacceptably long period of time.

In the particular case of the Canary Islands, the installation of wind farms is regulated through wind power tenders instigated by the Canarian Government through legislative decrees [12]. Normally only a short period of time is given between publication of these legislative documents and the deadlines for the presentation of proposals. As a consequence, a 
measurement wind data campaign is usually limited to just one year.

The wind farm developers undertake the economicfinancial studies and submit their corresponding proposals with the wind information collected over this period of time.

The wind farms presently installed in the Canarian Archipelago are generally found in the areas of highest wind potential. At the end of 2009, the total installed wind power in the islands was $141 \mathrm{MW}$. The strategic target set by the Canarian Government is to have 1025MW installed wind power by 2015 [13].

The new onshore wind farms that will be installed in the future will have to be sited in areas with less wind potential than the areas that are currently being exploited. Given the shape of the partial load zone of the powerwind speed curves of the wind turbines, the costeffectiveness of these installations will be more sensitive to wind speed variations.

In order to get around the afore mentioned inconvenience, the mean interannual wind performance at the candidate site can be estimated through statistical methods. These methods $[3,4]$ rely on the existence of reference stations installed at nearby sites for which longterm measurements (10 or more years) of the wind resource are available. These methods also require the results of a relatively short-term (normally one year) wind data measurement campaign at the candidate site. In addition, part of the wind data available for the reference station must coincide in length of time and date with the data measured at the candidate site.

Among the various methods used, some employ automatic learning techniques [14-19] which take their inspiration from statistical learning algorithms, such as Bayesian Networks (BNs) [14] and Artificial Neural Networks (ANNs) [15-19], the latter from the biological science field. In the other hand, there are methods that use traditional Measure-Correlate-Predict (MCP) algorithms [20-21].

In this paper, ANNs have been used as a tool to estimate the mean wind speed and wind power at a candidate station for which only incomplete wind data series are available.

The ANNs used in this paper were comprised of three layer networks with feedforward connections. More specifically, multilayer perceptron topologies (MLPs) were used [22-23]. A single hidden layer with 15 neurons was employed so as not to increase the training time. This architecture has demonstrated its ability to approximate satisfactorily any continuous transformation [22-23].

In general, only the wind speeds recorded at reference stations are used as signals of the input layer of multilayer perceptron (MLP) architectures. The output layer represents the candidate station wind speeds.

In addition to the corresponding mean wind speeds, the mean hourly wind directions are also used in the input layers.

In this study, wind power densities estimated through the use of ANNs will be compared with those obtained when considering the short-term wind data period (one year) of the candidate site to be representative of the long-term wind performance at the same site.

Different metrics will be used to assess this comparative analysis: the Mean Absolute Relative Error (MARE (1)) and Pearson's correlation coefficient between measured and estimated data (CC (2)).

$$
\begin{gathered}
C C=\frac{\sum_{i=1}^{n}\left(O_{i}-\bar{O}\right)\left(E_{i}-\bar{E}\right)}{\sqrt{\left[\sum_{i=1}^{n}\left(O_{i}-\bar{O}\right)^{2}\right] \times\left[\sum_{i=1}^{n}\left(E_{i}-\bar{E}\right)^{2}\right]}} \\
\text { MARE }=\frac{1}{n} \sum_{i=1}^{n} \frac{\left|O_{i}-E_{i}\right|}{O_{i}}
\end{gathered}
$$

Where $\mathrm{E}_{\mathrm{i}}$ are the estimated data and $\mathrm{O}_{\mathrm{i}}$, are the observed or measured data and $n$ is the number of data

\section{Meteorological data used}

The meteorological data used in this paper (mean hourly wind speeds and directions) were recorded over the years 1999-2008 at six weather stations installed on six different islands in the Canarian Archipelago (Spain). This information was provided by the State Meteorological Agency (Spanish initials: AEMET), linked to the Ministry of Environmental, Rural and Marine Environs of the Spanish Government.

In table I, the general data of the weather stations can be studied. Table II shows the wind speed correlation coefficients (3) between the different weather stations used. It has been calculated using all the period of time available. 
Table I: Weather stations used in the study

\begin{tabular}{|c|c|c|c|c|c|c|}
\hline \multirow[b]{2}{*}{$\begin{array}{l}\text { WEATHER } \\
\text { STATION }\end{array}$} & \multirow[b]{2}{*}{$\begin{array}{c}\text { YEARS OF } \\
\text { DATA } \\
\text { AVALIABLE }\end{array}$} & \multirow[b]{2}{*}{ HEIGHT } & \multicolumn{3}{|c|}{ Geographical Coordinates } & \multirow[b]{2}{*}{$\begin{array}{c}\text { LONG-TERM } \\
\text { ANNUAL MEAN } \\
\text { WIND SPEED } \\
(\mathrm{m} / \mathrm{s})\end{array}$} \\
\hline & & & $\begin{array}{c}\text { Latitude } \\
(\mathrm{N})\end{array}$ & $\begin{array}{c}\text { Longitude } \\
\text { (W) }\end{array}$ & $\begin{array}{l}\text { Altitude } \\
(\mathrm{m})\end{array}$ & \\
\hline WS-1 & 1999-2008 & 10 & $27^{\circ} 55^{\prime} 44^{\prime \prime}$ & $15^{\circ} 23^{\prime} 20^{\prime \prime}$ & 16 & 7,14 \\
\hline WS-2 & 1999-2008 & 10 & $28^{\circ} 57^{\prime} 7^{\prime \prime}$ & $13^{\circ} 36^{\prime}$ & 10 & 5,82 \\
\hline WS-3 & 1999-2008 & 10 & $28^{\circ} 27^{\prime} 10^{\prime \prime}$ & $13^{\circ} 51^{\prime} 54^{\prime \prime}$ & 24 & 5,83 \\
\hline WS-4 & 1999-2008 & 10 & $28^{\circ} 2^{\prime} 35^{\prime \prime}$ & $16^{\circ} 34^{\prime} 16^{\prime \prime}$ & 51 & 5,64 \\
\hline WS-5 & $1999-2008$ & 10 & $28^{\circ} 36^{\prime} 47^{\prime \prime}$ & $17^{\circ} 45^{\prime} 36^{\prime \prime}$ & 85 & 4,82 \\
\hline WS-6 & 1999-2008 & 10 & $27^{\circ} 48^{\prime} 50^{\prime \prime}$ & 17º53'10" & 30 & 5,96 \\
\hline
\end{tabular}

Table II: Linear correlation coefficients, R, between the wind speeds of the different anemometer weather stations.

\begin{tabular}{|c|c|c|c|c|c|c|}
\hline & \multicolumn{7}{|c|}{ Long-Term Correlation Coefficient (R). } \\
\hline & WS-1 & WS-2 & WS-3 & WS-4 & WS-5 & WS-6 \\
\hline WS-1 & 1,00 & 0,67 & 0,67 & 0,49 & 0,57 & 0,47 \\
\hline WS-2 & 0,67 & 1,00 & 0,65 & 0,49 & 0,49 & 0,44 \\
\hline WS-3 & 0,67 & 0,65 & 1,00 & 0,51 & 0,52 & 0,46 \\
\hline WS-4 & 0,49 & 0,49 & 0,51 & 1,00 & 0,38 & 0,26 \\
\hline WS-5 & 0,57 & 0,49 & 0,52 & 0,38 & 1,00 & 0,49 \\
\hline WS-6 & 0,47 & 0,44 & 0,46 & 0,26 & 0,49 & 1,00 \\
\hline
\end{tabular}

$$
R=\frac{\sum_{i=1}^{n}\left(V r_{i}-\overline{V r}\right)\left(V c_{i}-\overline{V c}\right)}{\sqrt{\left[\sum_{i=1}^{n}\left(V r_{i}-\overline{V r}\right)^{2}\right] \times\left[\sum_{i=1}^{n}\left(V c_{i}-\overline{V C}\right)^{2}\right]}}
$$

Where $\mathrm{Vr}_{\mathrm{i}}$ and $\mathrm{Vc}_{\mathrm{i}}$ are the measured wind speeds at the reference and candidate weather station, respectively. $\overline{\mathrm{Vr}}$ and $\overline{V_{C}}$ are the mean wind speeds at the reference and candidate weather station.

\section{Methodology}

The different metrics used in this paper have been assessed from the follow two hypotheses.

Hypothesis A: The long-term wind resource is estimated using the Artificial Neural Networks (ANNs).

The Long-Term wind data estimation process only used those weather stations from which there were 10 years worth of wind data.

In the creation of the networks, only one of the years of data collection was used (in this case, it was year 2008). The weather information was divided into two random subsets of different data: training data and validation data. The proportion of data selected for each of these processes was $80 \%$ and $20 \%$, respectively.

The training data subset is used for estimation of the weights of the ANNs. The validation data subset is used to check the training progress of the ANNs, and thus allowing the optimization of their parameters. That is, they are used to measure the degree of generalisation of the ANNs.

Wind data on the remaining years at the reference station were used to estimate long-term data in the candidate station. The different metrics that will be used in the analysis were calculated on comparing estimated and observed data.

The input signals of the network include the series of wind speeds and wind directions of a reference station. Output signals, on the other hand, included the series of wind speeds of the candidate station. In these models, the wind direction signal is introduced as angular magnitude $\left(0^{\circ}-360^{\circ}\right)$. Notice that the angle corresponding to the northerly direction is taken as angle $0^{\circ}$ (Figure 1 )

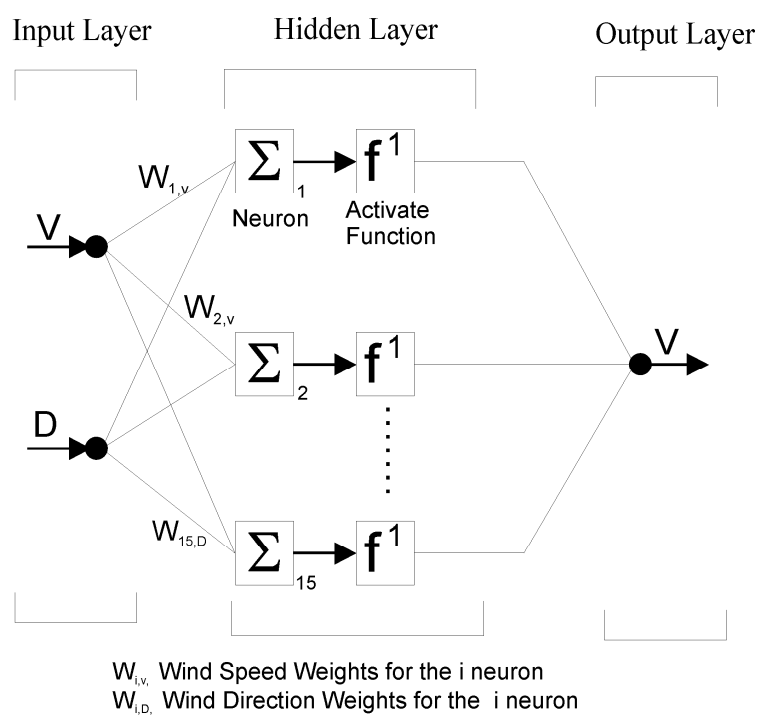

Fig. 1. Schematic diagram of an ANN with the wind speed (V) and the wind direction (D) of one Reference weather station as input signals, and the wind speed (V) of one Candidate (target) station as output signal.

Hypothesis B: Short term wind data is considered as the long term wind resource performance. 
In this case there is not a reference station. The short term wind data observed of the candidate station are considered as the long term wind resource performance. These one will be used to calculate long term wind power at the candidate site.

\section{Analysis of Results}

Table III shows the results obtained for the MARE of the wind speed (2) in the case hypothesis B. Data from each year have been considered as estimated data, whilst longterm measured data have been calculated from all available data (4).

$$
V_{j}^{L T}=\frac{1}{m} \sum_{i=1}^{m} V_{j, i}^{S T}
$$

Where $V_{j}^{L T}$, is the measured long-term wind speed in the instant of time $\mathrm{j} ; V_{j, i}^{S T}$, is the measured short-term wind speed in the instant of time $j$ and year $i$; and $m$, is the available number of years

The last row in table III shows the mean results for the MARE for every weather station. With these results it is possible to assess the mean value for the MARE of the wind speed for the six weather stations. Its value is 0.46 .

Table III: MARE of the wind speed when considering the short-term data to be representative of the long-term wind performance

\begin{tabular}{|c|c|c|c|c|c|c|}
\cline { 2 - 7 } \multicolumn{1}{c|}{} & \multicolumn{7}{|c|}{ Candidate Weather station } \\
\hline & WS-1 & WS-2 & WS-3 & WS-4 & WS-5 & WS-6 \\
\hline $\begin{array}{c}\text { year considered as } \\
\text { the long Term }\end{array}$ & \multicolumn{7}{|c|}{ MARE of the wind speed } \\
\hline 1999 & 0,40 & 0,38 & 0,34 & 0,45 & 0,35 & 0,35 \\
\hline 2000 & 0,54 & 0,48 & 0,43 & 0,50 & 0,39 & 0,48 \\
\hline 2001 & 0,52 & 0,51 & 0,44 & 0,59 & 0,45 & 0,63 \\
\hline 2002 & 0,49 & 0,47 & 0,43 & 0,60 & 0,46 & 0,56 \\
\hline 2003 & 0,49 & 0,51 & 0,45 & 0,55 & 0,47 & 0,54 \\
\hline 2004 & 0,52 & 0,45 & 0,45 & 0,52 & 0,47 & 0,54 \\
\hline 2005 & 0,45 & 0,44 & 0,45 & 0,45 & 0,47 & 0,56 \\
\hline 2006 & 0,44 & 0,44 & 0,37 & 0,52 & 0,52 & 0,52 \\
\hline 2007 & 0,44 & 0,42 & 0,37 & 0,48 & 0,45 & 0,39 \\
\hline 2008 & 0,40 & 0,38 & 0,35 & 0,44 & 0,39 & 0,36 \\
\hline Mean Results & $\mathbf{0 , 4 7}$ & $\mathbf{0 , 4 5}$ & $\mathbf{0 , 4 1}$ & $\mathbf{0 , 5 1}$ & $\mathbf{0 , 4 4}$ & $\mathbf{0 , 4 9}$ \\
\hline
\end{tabular}

To estimate the long term wind resource with the ANNs' method, the speed and direction of the wind from only one reference station has been used as in the input layer parameter. Each long term wind performance has been calculated taking the rest of the weather station (one by one). Therefore, there will be five different estimations for each weather station. In figure 2 is compared the results obtained with those of hypothesis B (Table III)

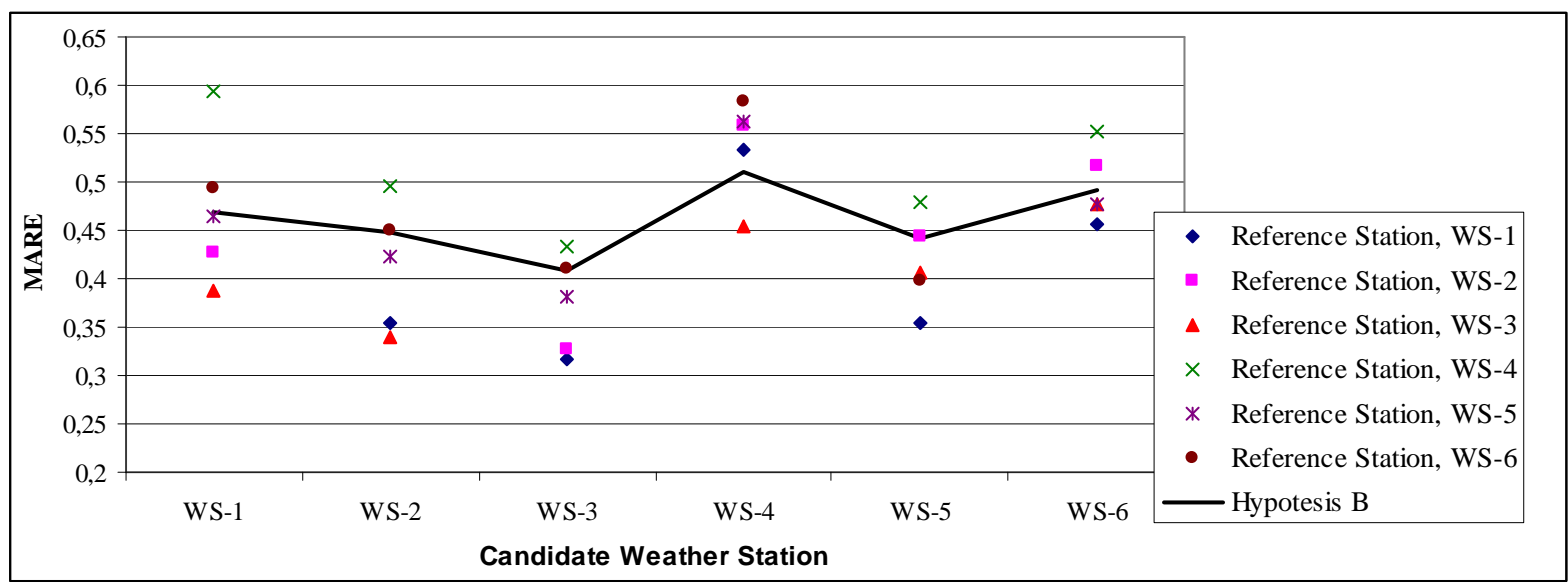

Fig. 2. Comparison of the MARE of the wind speed for each weather station when it is used the ANNs with one reference station to estimate long-term wind speed (Hyp. A), with the case where is used the short-term data to be representative of the long-term wind performance (Hyp. B) 
It is observed that in the long term estimation with ANNs, the best results are obtained when the correlation coefficient, $\mathrm{R}$, between the wind speed of the candidate and reference weather station is largest. The worst results are obtained in opposite cases.

In four of the total six cases, where $\mathrm{R}$ is between 0.5 and 0.6 (see figure 3 and table II), the MARE of the wind speed for hypothesis A is better than that for hypothesis B. When R (3) is highest (up to 0.6), the results for hypothesis $\mathrm{A}$ are better in all cases.

From the six cases where $\mathrm{R}$ are between 0.5 and 0.6 (see figure 3 and the table II), in four of them, the MARE of the wind speed in the hypothesis $\mathrm{A}$ are better than in the hypothesis B. When $\mathrm{R}(3)$ is greater than 0.6 , the results for the hypothesis A are better in all of the cases.
As mentioned by S. Velázquez et al[18], when more weather stations are added to the input layer in the ANNs' method, the estimation are always better whatever be the correlation coefficient between the second and follows weather station added with the candidate weather station.

As mentioned by S. Velázquez et al [18], the larger the number of weather stations added to the input layer using the ANNs' method, the better performance of the estimation. This is true, regardless of the correlation coefficient, $\mathrm{R}$, for the second and consecutive stations added, as well as for the candidate weather station. It is therefore possible for this conclusion to be generalized for any correlation coefficient smaller than 0.6.

Figure 3 shows the comparison for the correlation coefficient existent between measured and estimated wind speed, CC (1), for hypotheses A and B.

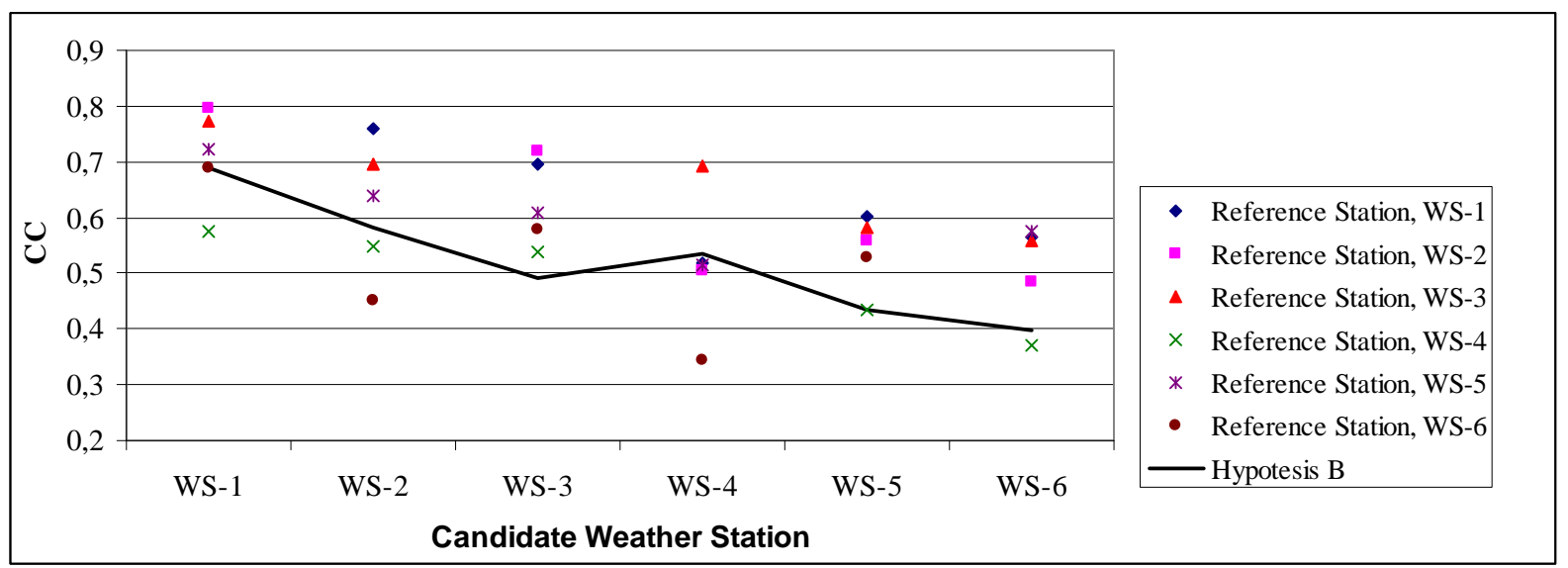

Fig. 3. Comparison of the metric CC when it is used the ANNs to estimate long-term wind speed (Hyp. A), with the case where is used the short-term data to be representative of the long-term wind performance (Hyp. B)

For the CC, the conclusions reached (figure 3) are the same as those for the MARE of the wind speed (figure 2). That is, results for the CC are better the greater the value of R. For correlation coefficients, R, greater than 0.6, better results have been obtained for hypothesis A than for hypothesis B.
If more weather stations are included in the input layer of the ANNs' model, results obtained will even be better [18].

For the MARE of the wind power (figure 4) results for hypothesis A as good or better that for hypothesis B for all of the cases, including when $\mathrm{R}$ is between 0.5 and 0.6.

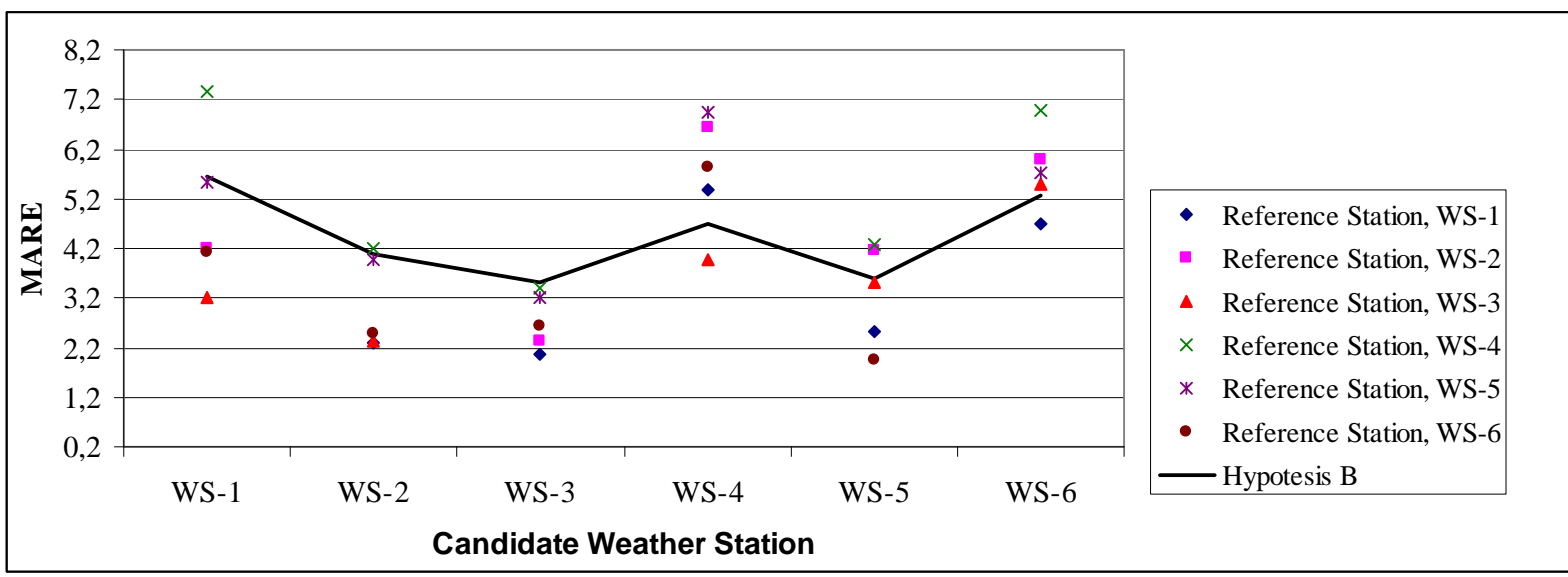

Fig. 4. Comparison of the MARE of the wind power for each weather station when it is used the ANNs with one reference station to estimate long-term wind speed (Hyp. A), with the case where is used the short-term data to be representative of the long-term wind performance (Hyp. B) 


\section{Conclusions}

When short-term data is taken to be representative of the long-term wind speed, the Mean Absolute Relative Error (MARE) of the wind speed and wind power (for all the studied cases with the different weather station), were 0.46 and 4.47 , respectively.

For all of the analyzed cases, if the correlation coefficient $\mathrm{R}$ (3) between the wind speeds of the candidate and reference weather station, is greater than 0.6 , the results in the estimation of long term wind resource with the Artificial Neural Networks methods (ANNs) is better than when using short-term data to be representative of the long term wind resource.

For the MARE of the wind power, the results obtained in the estimating using the ANNs' method also are better when $\mathrm{R}$ is in the range 0.5-0.6.

If more than one weather station is used in the input layer of the ANNs, it is possible to obtain a better result in the long term estimation than using a single station.

\section{References}

[1] TR. Hiester, WT. Pennell, The siting handbook for large wind energy systems. 1st ed. New York: WindBook, 1981.

[2] V. Conrad, LW Pollack, Methods in climatology. Second ed. Cambridge-Massachusetts: Harvard University Press, 1962. [3] JA. Carta, J. González, Self-sufficient energy supply for isolated communities: wind-diesel systems in the Canary Islands. The Energy Journal 2001, 22, pp 115-145.

[4] CI. Aspliden, DL Elliott, LL Wendell, Resources assessment method, siting, and performance evaluation. In: Guzzi R, Justus CG. Physical climatology for solar and wind energy, New Jersey: World Scientific; 1988, pp. 321-396.

[5] PC. Putnam, Power from the wind. 1st ed. New York: Van Nostrand Reinhold Company; 1948.

[6] GW Koeppl, Putnam's power from the wind. Second ed. New York: Van Nostrand Reinhold Company, 1982.

[7] CG. Justus, K. Mani and AS. Mikhail, Interannual and month-to-month variations of wind speed. Journal of Applied Meteorology 18, 1979, pp 913-20.

[8] PA. Daniels and TA. Schroede, Siting large wind turbines in Hawaii. Wind Eng 1988; 12, pp 302-330.

[9] Nelson V. Wind energy.1st. ed. FL: CRC Press; 2009.

[10] Hau E. Wind turbines. 2nd ed. New York: Springer; 2005

[11] Swift-Hook DT. Second wind. The Engineer 1988, 267, pp 30-31

[12] 32/2006 of 27 March Decree, which regulates the installation and operation of wind farms in the area of the Canarian Archipelago. BOC 61, 2006, pp 5855-5867

[13] 2006-2015 Energetic Plan of Canary Islands, 2005.

[14] JA. Carta, S. Velázquez, JM. Matías, Use of Bayesian Networks classifiers for long-term mean wind turbine energy output estimation at a potential wind energy conversion site, Energy Conversion and Management 52, 2011, pp 1137-1149.

[15] M. Bilgili, B. Sahin, A. Yasar, Application of artificial neural networks for the wind speed prediction of target station using reference stations data, Renewable Energy 32, 2007, pp 2350-2360.

[16] Kalogirou SA. Artificial neural networks in renewable energy systems applications: a review. Renewable and Sustainable Energy Reviews 5, 2001, pp 373-401.
[17] Mabel C, Fernandez E. Analysis of wind power generation and prediction using ANN: A case study. Renewable Energy 2008, 33, pp 986-992.

[18] S. Velázquez, JA. Carta, JM. Matías, Influence of the input layer signals of ANNs on wind power estimation for a target site: A case study, Renewable and Sustainable Energy Reviews, 15, 2011, pp 1556-1566

[19] DA. Fadare, The application of artificial neural networks to mapping of wind speed profile for energy application in Nigeria, Applied Energy, 87, 2010, pp 934-942.

[20] Rogers AL, Rogers JW, Manwell JF. Comparison of the performance of four Measure-Correlate-Predict algorithms. Journal of Wind Engineering and Industrial Aerodynamics 93, 2005, pp 243-264.

[21] Clive JM. Non-linearity in MCP with Weibull distributed wind speeds. Wind Engineering 2008, 32, 319-342.

[22] JC. Principe, NR. Euliano, WC. Lefebvre, Neural and Adaptive Systems. Fundamentals Through Simulations, first ed. New York: John Wiley \& Sons, Inc.; 2000.

[23] T. Masters, Practical Neural Network Recipes in C++, first ed. California: Morgan Kaufmann Publishers; 1993. 